\title{
LAS CONTRADICCIONES DEL CONTRATO DE LECTURA DE CARTAS MARRUECAS: EL CARÁCTER DE LA IMPARCIALIDAD POLÍTICA
}

\author{
Jorge Chen Sham
}

\begin{abstract}
RESUMEN
La preocupación constante del prólogo por dejar constancia de su imparcialidad política se vuelve casi una obsesión que ha obligado al autor a escamotear su responsabilidad (el artificio extranjerizante de un falso autor o la invención de un falso manuscrito encontrado fortuitamente) y a separarse constantemente de las dos malas interpretaciones que puede hacerse de sus cartas. Bajo tal clima de suspicacia, ¿cómo creer en su buena fe y en su sinceridad? ¿Por qué actúa así? La imparcialidad es insostenible allí donde falla la verdad y las dudas surgen. En palabras de Francesco Orlando, el gesto de precaución tendría como finalidad escamotear la censura misma a la que puede conducir el autor del texto y, por añadidura, engañar al censor ante un libro que es por naturaleza polémico y que acarrearía problemas para quien lo firma.
\end{abstract}

\begin{abstract}
The steadfast concern of the prologue as to making statement of its political impartiality becomes almost an obsession that has forced the author to filch his responsibility (the alienating device of a false author or the invention of a false manuscript found by chance) and to constantly stay away from the two misinterpretations that can be done about his letters. Under such a suspicious environment, ihow can one rely on his good faith and his sincerity? ¿Why does he act like that? Imparciality is unsustainable when truth fails and doubts arise. In the words of Francesco Orlando, the purpose of this gesture of precaution would be to avoid the very censorship to which the text's author can be driven and, moreover, to deceive the critic who stands before a book which is polemic by nature and which would bring trouble upon the person who signs it.
\end{abstract}

La deriva hermeneútica, con la que pretendemos analizar el proceso de recepción de las Cartas Marruecas de José Cadalso, tiene su origen en el contrato de lectura ofrecido por el espacio paratextual con el que el texto justifica su inserción dentro de la formación estético-literaria (Pérus 1981: 256-7). Así, todo texto literario nace con la imperiosa necesidad de adecuarse a reglas de producción-recepción que la práctica social le impone para circular con éxito, al mismo tiempo que el paratexto ofrece y destaca la correspondencia y la inserción del texto dentro del modo de discursividad vigente o, en su defecto, aclara las razones por las cuales se infringen tales normas discursivas. En el caso de Cartas Marruecas escritas por un imparcial político, el título de su primera edición por entregas, en el Correo de Madrid, tomos IV y V, desde el 14 de febrero al 25 de julio de 1789, enarbola precisamente la objetividad y 
el buen juicio con los que se acompañan no sólo los procedimientos de recolección de los materiales, sino también la etapa de la redacción y evaluación de tales materiales. De manera que el título del libro nos ubica por adelantado dentro de un modelo discursivo claramente identificable y repertoriado para los lectores contemporáneos a su primera puesta en circulación, el de la práctica historiográfica dieciochesca.

En ese sentido, recordemos que la renovación de la cultura del siglo XVIII se plantea como un ataque al monopolio de la teología escolástica y del aristotelismo sobre la vida intelectual española (Lopez 1976: 41-54), por lo cual el reformismo y el absolutismo ilustrados, con esa conciencia de proponer transformaciones socio-culturales y políticas, pretende acabar con las taras del pasado y sentar las bases para una sociedad próspera y feliz. Para ello, es necesario introducir los métodos de las ciencias experimentales y naturales, a saber, la observación y la experimentación como única vía para alcanzar la verdad científica. A tal programa corresponde el privilegio que se concede al sentido crítico riguroso, mediante la convergencia de datos y el trabajo de campo, este principio lo denominarán los novatores de la primera mitad del siglo el "criticismo"; Mestre explica que "(...)el criticismo (...) sólo acepta el hecho demostrado en fuentes fehacientes y, en concreto, en documentos auténticos. Habrá que establecer, por lo tanto, unos criterios rigurosos que pudieran dar validez científica a las fuentes documentales así como a las conclusiones inducidas por el historiador" (1986: 111).

De esta forma, cuando las Cartas Marruecas declaran su carácter imparcial, están remitiendo a la práctica historiográfica cuyos criterios de verificación y de análisis, a la hora de tratar cualquier objeto de estudio, destruyen las opiniones comunes y cuestionan la tradición heredada. Esta asociación entre criticismo y verdad acentúa la equivalencia con la noción de Historia y explicaría la manera en que la Historia emerge, en la mente de las élites dieciochescas, como el instrumento de análisis de la sociedad. Por lo anterior, el programa historiográfico ilustrado se transforma en un arma contra los errores y las falacias de la sociedad española y, principalmente, en un estudio exhaustivo, con pretensiones globalizantes, para esclarecer su estado y su naturaleza. He aquí la razón por la cual la historiografía despiaza su campo de observación hacia un análisis crítico de la situación de un país o de un pueblo, en el que interesan tanto sus movimientos y componentes como las causas y las fuerzan que interactúan: "En los hechos del pasado, la meditación filosófica tiene que descubrir las leyes de la naturaleza humana y explicar por ellas, en términos generales, el curso del acontecer (de una nación)" (Maravall 1966: 83).

Así, la extensión del concepto de Historia al ámbito de toda una sociedad permite su imbricación al campo nocional de la filosofía, en donde su equivalencia al término "política" es indudable si nos atenemos a su origen etimológico, de POLIS, "todo lo relacionado a la ciudad, es decir, al sistema de organización social", como nos lo reconfirma Gazel en la Carta LI: "(..) de donde se infiere que su verdadero sentido es la ciencia de gobernar los pueblos" (Cadalso 1983: 204). Por eso, el político es quien cultiva el estudio de una sociedad y el que se dedica a los problemas propios de una nación. Ahora bien el título pregona que las cartas han sido escritas por un "imparcial político", lo cual indica, por un lado, que se mantiene independiente y carente de prejuicio o adversión a personas o ideas para "poder juzgar u obrar con rectitud" (Alonso 1958: 2347, tomo II) y, por otro, que el examen y el análisis propuestos se realizan con el debido respeto al prurito historiográfico del criticismo, en donde el espíritu de análisis y de síntesis se convocan mutuamente. Por eso, aquí la función del político parece 
acercarse al ideal de filósofo ilustrado, un hombre útil "qui entend vivre en société et faire partager les fruits de sa sagesse à ses contemporains (...)" (Didier 1987: 305); es decir, que sabe actuar con razón y juzgar con mesura las costumbres y los hechos. El filósofo ideal se concibe, por esta razón, como un agudo observador que sabe sacar de los hechos conclusiones y principios de valor general. Lo mismo piensa Russell Sebold, cuando relaciona el "hombre de bien" al que aspiran las Cartas Marruecas con la figura del filósofo ilustrado, el cual "se guía en todas las cuestiones por la razón, y que une a un espíritu de reflexión y precisión las maneras y los rasgos de sociabilidad" (1974: 204). Por lo tanto, en las palabras acertadas de Glendinning, es el hombre virtuoso el que examina y analiza una sociedad con miras a buscar la verdad y la virtud (1962: 89).

Continuando con nuestras observaciones, este carácter imparcial del texto se proyecta de nuevo al presentar el otro modelo discursivo sobre el que se funda el contracto paratextual, el de la epistolografía, cuyo doble valor viene marcado, desde la antigüedad greco-latina, por ser testimonio y confesión de un individuo y por ser documento biográfico-histórico (Boissier 1900: 4-5). A lo anterior, cabe agregar lo que descodifica acertadamente el prólogo alógrafo ${ }^{1}$, cuando apunta que estas cartas adquieren la forma enunciativa de crónica de un viaje escrita por unos ojos "imparciales":

(...) son las que llevan el nombre de Cartas, que suponen escritas en este u aquel país por viajeros naturales de reinos no sólo distantes, sino opuestos en religión, clima y gobierno. El mayor suceso de esta especie de críticas debe atribuirse al método epistolar, que hace su lectura más cómoda, su distribución más fácil, y su estilo más ameno, como también a lo extraño del carácter de los supuestos autores (...) (Cadalso 1983: 77-8)

Más allá de la justificación estilística que conlleva la cita, el prólogo inserta las Cartas Marruecas en la tradición genérica del viaje, cuya expansión y éxito, a lo largo del siglo, se debe al doble interés dieciochesco de difundir los avances de la historia, la geografía y las otras ciencias y, principalmente, de satisfacer la curiosidad del lector ilustrado interesado por los espacios exóticos y desconocidos (Lafarga 1994: 173-4). En este sentido, el viaje o el relato de viajes ofrecían una masa de información sobre lugares y civilizaciones lejanas e ignotas tanto para el emisor como para los destinatarios potenciales. Así, los relatos de viajes muestran un afán de conocimiento que comparte el viajero-narrador con sus lectores, pues estos textos parten del presupuesto de que se escribe para un público que busca ávidamente cultivarse y entretenerse con ellos ${ }^{2}$. Cabe aquí anotar que la ficción literaria se apropia de esta tradición de los viajes "para la expresión de una sensibilidad o de una crítica social" (Lafarga 1994: 181), en donde el viaje imaginario desempeña inequívocamente una función política (Zavala 1984: 31), como queda explícito en el título-sumario ofrececido por el palimpsesto que le sirve de base al prologador-editor y que señala el contenido y materia del libro: “(...) sobre los usos y costumbres de los españoles antiguos y modernos (...)" (Cadalso 1983: 78).

De esta manera, contigüidad obliga, el "imparcial político" del título se descodifica en el prólogo como un viajero extranjero, es decir, ajeno al país que visita y recorre. En este caso, se trata de las cartas escritas por un viajero marroquí llamado Gazel Ben Aly y que recorre la corte española con el mandato expreso de aprender; su nacionalidad era totalmente plausible para los lectores españoles pues trae a colación la embajada histórica que hizo el emisario del monarca de Marruecos y cuyo nombre era Sidi Hamet El Gazel ${ }^{3}$. Así, no sólo la refe- 
rencia de un viajero marroquí hace verosímil el texto, sino también se justifica la atención que pone sobre aspectos de la sociedad española, por lo cual las cartas serán la expresión tanto de las observaciones como de los comentarios que a Gazel le impresionen y le interesen de ese espacio ignoto 4 . Por otra parte, para Russell Sebold la imparcialidad que esgrime el texto se fundamenta también en la tradición genérica de los libros de viajes que, al abordar la pluralidad de costumbres, ritos, formas de gobierno y de religión catalogados como exóticos y diferentes, no tienen más remedio que plantear "una tolerancia racional nacida del casamiento del punto de vista internacional con la observación de las costumbres locales" (1974: 201).

Vistas así las cosas, este distanciamiento (la extranjería) es lo que posibilita, en primera instancia, el criterio de imparcialidad y determina la actitud de un observador que, a partir de lo que mira y describe, estima que sólo de los hechos particulares y de los detalles podrá extraer conclusiones para esclarecer el estado de un país. Por eso, en la cita apuntada más arriba, el prologador insiste en el éxito de este tipo de relatos de viaje escritos en forma epistolar, pues la necesidad de un efecto verosimilizante como es el de un observador ajeno y distanciado se ajusta a las demandas del criticismo dieociochesco (Chen 1994a: 8-9). Por esa razón, ajustándose a este prurito de la verdad y al hecho de que la extranjería permite un acercamiento a la imparcialidad, el espíritu de análisis del cual se nutre las Cartas Marruecas conduce al prologador-editor de las cartas, en tanto lector calificado del texto y crítico conspicuo, a ponderar el valor del justo medio en materia de crítica social, no sin antes aclarar que el texto no atenta contra la censura que prohíbe los temas "de religión ni de gobierno" (Cadalso 1983: 79), que ya hemos comentado anteriormente 5 . Y es que cuando se hace una crítica al "carácter nacional" presente y pasado, el prologador-editor de las Cartas Maruecas no puede sustraerse de que las leyes españolas pedían la circunspección y la seriedad en los campos de la política, la religión y la moral (Domergue 1982: 112-3). No olvidemos tampoco que, durante la década de los 80, Forner y el propio Cadalso estuvieron a la cabeza de un movimiento de crítica y cuestionamiento de la cultura española; esta polémica los enfrentó, paradójicamente, a una gran parte de intelligentsia ilustrada pero sobre todo a grupos asociados al partido castizo ${ }^{6}$.

Por lo anterior, en cuanto receptor y lector doblemente calificado (intérprete y crítico), según la caracterización de Iris Zavala (1983: 510-1), el prologador-editor es quien otorga, en primer lugar, el sentido político a las cartas y tal selección compromete su labor como responsable del circuito de comunicación y, en segundo lugar, lo obliga a adecuar el comentario sobre el libro, en vista de que ha arriesgado una interpretación que puede suscitar controversias y reparos. Desde esta perspectiva, Genette señala que una de las principales funciones del prólogo es ponderar la importancia del tema insistiendo en su utilidad (Genette 1987: 185), en este caso se trata de utilidad política; pero al efectuar esta valoración, el prólogo de las Cartas Marruecas se desliza hacia una función complementaria, la novedad en el tratamiento del tema (1987: 186). Esta insistencia en la novedad del tratamiento se hace con una conclusión que pone en evidencia cómo, en materia de crítica de una nación, el autor de las cartas no se inclinó ni por el panegírico ni por la sátira destructiva:

Para manejar esta crítica al gusto de algunos, sería preciso ajar la nación, llenarla de improperios y no hallar en ella cosa alguna de mediano mérito. Para complacer a otros, sería igualmente necesario alabar todo lo que nos ofrece el examen de su genio, y ensalzar todo lo que en sí es reprehensible. Cualquiera de estos dos sistemas que se siguiese en las Cartas Marruecas tendría gran número de apasionados; y a costa de mal conceptuarse con unos, 
el autor se hubiera congraciado con otros. Pero en la imparcialidad que reina en ellas, es indispensable contraer el odio de ambas parcialidades. Es verdad que este justo medio es el que debe procurar seguir el hombre que quiera hacer algún uso de su razón (...) (Cadalso 1983: 81)

La novedad en el tratamiento radica en su imparcialidad y, en este sentido, alude el texto al ideal de filósofo-político que posee la Ilustración en cuanto hombre de razón, un hombre que busca la verdad ante todo y se guía por un espíritu crítico, el cual requiere precisión de los datos y rigor en el estadio de la recolección como en el procesamiento de estos datos; es lo que podemos llamar método siguiendo a Juan de Aravaca en su dictamen a las Memorias literarias de París de Ignacio de Luzán (1751):

(...) pide una sabia y experimentada dirección, que disponga con orden las materias; de modo que, sirviendo las unas de preparación para las otras, se instruya el estudioso de todas ellas con solidez y fundamento, sin confundirse con la variedad y multitud de especies. este orden y disposición se llama Méthodo (...) (citado por Maravall 1981: 188)

A partir de lo anterior, podemos comprender cómo el prologador-editor de las Cartas Marruecas retoma ahora el carácter imparcial para valorar la competencia del autor a la hora de escribir su libro, ya que es necesario reconocer su respeto a las reglas de codificación historiográfica. Estas reglas presuponen que el autor ha evitado los juicios de valor y los comentarios impertinentes, se ha adecuado también a los hechos y ha proporcionado información sometida previamente a la verificación; para tal fin se vale de su competencia y autoridad, fruto de su trabajo. Ahora bien, destacar el carácter imparcial le sirve, además, para neutralizar cualquier objeción por parte de lectores disidentes que no quisieran aceptar su punto de vista, de este modo el prologador funciona como garante de la palabra del autor. He aquí explicitado cuál es el contrato de lectura que nos propone el prólogo, por lo que habría que analizar si, en efecto, su proceso de validación culmina en éxito o en fracaso "(...)pour être validée, acceptée par le consensus social des participants au dialogue, et échapper ainsi à toute sanction ou mesure de rétorsion de leur part" (Berrendonner 1981: 63). El proceso de recepción truncado de las Cartas Marruecas demostraría, precisamente, el fracaso de la imparcialidad del texto, pues, leído bajo el protocolo de sátira que denigra la nación, los calificadores del Consejo de Castilla, sancionan de parcial a su autor. En este sentido, si se insiste tanto en la imparcialidad es porque hay miedo de que haya lectores hostiles que no se dejen persuadir por las declaraciones del mismo prólogo o, en su defecto, que después de leer la totalidad del corpus epistolográfico saquen esa conclusión, de manera que por adelantado se desarma este reparo. ¿Por qué no tiene éxito el contrato del prólogo? ¿Por qué no basta la precaución de extranjería?

La respuesta empieza en el propio prólogo de las Cartas Marruecas, pues el propio prologador justifica, a su manera, las consecuencias a las que lo conduce la imparcialidad con la que también ha realizado su trabajo de edición e insiste en que no seguirá el aparato excesivo de los procedimientos de la codificación historiográfica que, por añadidura, hablarían de la competencia y autoridad del erudito editor, cuando le corresponde hacer lo contrario; todo debe servir para destacar la obra del autor 7 :

Para desagravio de mi vanidad y presunción, iba yo a imitar el método común de los que, hallándose en el mismo caso de publicar obras ajenas a falta de suyas propias, las cargan de no- 


\begin{abstract}
tas, comentarios, corolarios, escolios, variantes y apéndices; ya agraviando el texto, ya desfigurándolo, ya truncando el sentido, ya abrumando al pacífico y muy humilde lector con noticias impertinentes, o ya distrayéndole con llamadas importunas, de modo que, desfalcando al autor de mérito genuino, tal cual lo tenga, y aumentando el volumen de la obra, adquieren para sí mismos, a costa de mucho trabajo, el no esperado (...) (Cadalso 1983: 79-80)
\end{abstract}

Cuestiona aquí el prologador la costumbre de cargar los trabajos historiográficos, en apego literal a los principios del criticismo, de un excesivo aparato de erudición que faltaría a la concisión y a la brevedad que se le pediría al editor-prologador de un libro hecho por un tercero; sin embargo, al defenderse de lo que no realiza expone una justificación, seguir la tradición en materia de verificación y precisión de los datos con un aparato formal crítico. De esta manera, pareciera, a simple vista, que la presentación de las Cartas Marruecas se desarrolla como un prólogo que se ocupa únicamente de la obra y del tratamiento del tema, tal y como lo exige la retórica del paratexto (Chen 1991); ahora bien, en la segunda mitad del siglo XVIII he percibido una diferencia entre prólogo y epístola-dedicatoria a la que debo hacer referencia para plantear mejor lo que sucede en el texto en estudio. Antonio de Capmany, en su "Discurso Preliminar" al Teatro histórico-crítico de la eloquencia española, desarrolla la diferencia en términos de la presencia/ausencia del autor:

(...)los modernos los extienden en doctas prefaciones, en discursos preliminares o en prólogos
bien racionados, donde se satisface la curiosidad de los lectores, se justifican las intenciones de
los autores y se presenta el diseño de toda la obra. Nuestros antepasados no conocían más que
prólogos breves y diminutos, en que suelen hablar más de la utilidad de la Historia en general
y de sus excelencias, que de la bondad y provecho de la particular que publicaban. Algunos de
aquellos prólogos podíanse llamar hemafroditas, pues hacían a epístola dedicatoria al mismo
tiempo, donde el autor habla más de sí que de la obra; reduciendo a veces toda la substancia
de este preámbulo a encarecer sus trabaxos, sus tareas, sus vigilias, a pedir perdón a sus lecto-
res (...) delatando sus yerros, su pobreza de estilo (...) (1786: XXVI)

Queda claro que la presencia del autor sirve como rasgo genérico que marca el límite entre prólogo y epístola-dedicatoria, por lo cual será más atinado ubicar ahí todas las muestras de subjetividad y de defensa del autor en sí. A luz de esta precisión, podemos comprender cómo el prólogo de las Cartas Marruecas resumía lo que era el mérito y la utilidad del libro; pero al abordar las razones por las cuales el corpus epistolográfico se presenta sin el aparato crítico de rigor reduciéndolo según el criterio del prologador al mínimo, con el fin de que se otorgue más importancia y atención a aquél, se produce un deslizamiento hacia la figura del autor, delatando no "sus yerros" como afirma Capmany, sino el equívoco sobre el cual se funda el artificio autorial y que tiene su origen en la confusión de sujetos a los que se atribuye la autoría. Veamos con atención lo que afirma el prologador:

Si yo me pusiese a publicar con dicho método las obras de algún autor difunto siete siglos ha, yo mismo me reiría de la empresa, porque me parecería trabajo absurdo el de indagar lo que quiso decir un hombre entre cuya muerte y mi nacimiento habían pasado seiscientos años; pero el amigo que me dejó el manuscrito de estas Cartas y que, según las más juiciosas conjeturas, fue el verdadero autor de ellas, era tan mío y yo tan suyo, que éramos uno propio; y sé yo su modo de pensar como el mío mismo, sobre ser tan rigurosamente mi contemporáneo, que nació en el mismo año, mes, día e instante que yo (...) (Cadalso 1983: 80)

En primer lugar y en concordancia con lo que venía explicando, el prologador justifica la reducción del aparato crítico en la imposibilidad que posee el editor en averiguar a cien- 
cia cierta lo que pensó y quiso decir, con cada palabra, el autor; después atribuye la autoría al amigo suyo, de quien recuperó fortuitamente el manuscrito de las Cartas escritas por un moro llamado Gazel Ben-Aly y, en este sentido, empiezan a emerger las contradicciones. Inmediatamente afirma que su amigo y él se parecen tanto que son una misma persona y se confunden en su identidad, de modo que, si lo conoce tan bien, ¿cómo no pudo interpretar su pensamiento y no tendría que haber, por esa razón, pasajes dudosos y oscuros? Es más, él atribuye estos pasajes a la extranjería del moro o a los descuidos o a las interpolaciones de los copistas, remitiendo de esta manera al tópico de los falsos cronicones y de la invención de fuentes que pueblan los textos literarios del siglo XVIII. Estos procedimientos explican la estrategia narrativa que ofrece la literatura para responder y ocultar su naturaleza ficticia, dejando que aparezca la instancia productora del relato; en palabras de Lucien Dällenbach es "feindre de laisser le responsable du récit intervenir en son nom propre, instituer un narrateur, construire une figure auctoriale et la faire endosser à un personnage" (1977: 101). Surge en las Cartas Marruecas una especie de falsificación por el cual el verdadero autor del texto hasta ahora invisible, mediante la trampa en la que caemos los lectores, se susbtituye al pretendido autor y se le acredita a él la paternidad del texto, en el sentido de que surge el "destinador" último en esta cadena de pretendidos autores.

Sin embargo, en otro lugar y en relación con el Fray Gerundio de Campazas (Chen 1995), he analizado de otra manera esta estrategia que implica escamotear la responsabilidad frente a la palabra ${ }^{8}$ y que crea una situación comunicativa que pone en entredicho la práctica historiográfica sobre la que se fundan ambos textos. El problema estriba en saber si la instancia prologal ha mentido y nos ha tomado el pelo, lo que es aún más grave, pues, en un primer momento, la autoría la cede al viajero extranjero, para después acreditársela él mismo en la figura de un amigo que parece su doble. Así, al definir la mentira como "decir lo contrario de lo que uno piensa con la intención de engañar" (Camps 1989: 32, cursiva de la autora), introducimos el acto de doblez constituyente de toda mentira, en "la encubierta inconexión entre lo que digo y lo que, de hecho, pretendo conseguir sin que el otro lo aperciba, puesto que se trata de engañarle" (Camps 1989: 33). La mentira es manipulación y aquí el prologador y pretendido editor lo hace suspendiendo el contrato de autenticidad y de fidelidad propios del criticismo imparcial del XVIII; se trata entonces de una ruptura de la fe en lo que propone el prólogo con la subsiguiente suspensión de la imparcialidad que funda el texto. ¿Cómo puede haber imparcialidad ahí en donde sería el propio autor el que presenta su obra y programa una determinada lectura aséptica del texto que respondería a posibles reparos de lectores hostiles?

En este sentido, Genette afirma que todo prólogo arriesga una interpretación que sirva de garantía y de precaución para los malos usos de la ficción literaria y, en el caso de las Cartas Marruecas, esgrimiendo la pretendida imparcialidad, enarbola las dos interpretaciones nocivas del texto. El prólogo explica estas dos interpretaciones como si fueran partidos que, según el Diccionario de Autoridades son "(p)arcialidades o coligación entre los que siguen una misma opinión o interés" (1979: 141, tomo III). Desde este punto de vista, según el mismo Diccionario, todo partido es por naturaleza parcial $^{9} \mathrm{y}$ ante estas dos posiciones que se ven como antagónicas en materia de la crítica social, él que se considera un político, debe rechazar tanto el panegírico del que encuentra únicamente cosas buenas en la tradición española, como la chanza del que rechaza ésta misma: 


\begin{abstract}
Por ejemplo, un español de los que llaman rancios irá perdiendo parte de su gravedad, y casi llegará a sonreírse cuando lea alguna especie de sátira contra el amor a la novedad; pero cuando llegue al párrafo siguiente y vea que el autor de la carta alaba en la novedad alguna cosa útil, que no conocieron los antiguos, tirará el libro al brasero (...) Por la contraria, cuando uno de estos que se averguienzan de haber nacido de este lado de los Pirineos vaya leyendo un panegírico de muchas cosas buenas que podemos haber contraído de los extranjeros, dará sin duda mil besos a tan agradables páginas (Cadalso 1983: 82)
\end{abstract}

De manera que el prólogo previene, ya sea contra las críticas acérrimas de los que se aferran a las costumbres antiguas, ya sea contra los inmoderados elogios de los que adoptan sin pensar todo lo que proviene del exterior. Cabe destacar que Maravall resume muy bien lo que se juega en ambas posiciones que el prólogo simplifica entre un partido castizo y un partido ilustrado de la siguiente manera: "(...)unos no gustan del estado a que ha llegado el país, y con esta actitud crítica, quieren recoger de la historia sólo lo que apoya su programa reformador; otros, se cierran contra éste y levantan el muro de la sumisión al pasado. El hombre de mentalidad tradicionalista hacía del pasado norma de obligatorio acatamiento; el hombre ilustrado presentaba a la historia como el panorama de todos los errores humanos" (1966: 88). Y frente a estas dos posiciones, frente a estos dos partidos o dos posiciones parciales, hay críticos contemporáneos que, dejándose llevar por la buena fe que aparentemente esgrime el prólogo, aceptan con facilidad las palabras del autor y se apresuran a catalogarlo como imparcial; sirva de ejemplo lo que Mariano Baquero Goyanes afirma:

El autor en la Introducción, proclama esa neutralidad crítica suya (...) Entre el santonismo de la tradición y el extrajerizante y beato culto al progresismo, Cadalso evita uno y otro extremo, y sitúa su muy española crítica a tono con su tiempo y a tono también con el pasado de su patria (1963: 19, cursiva del autor)

Ahora bien, esta anticipación de las reacciones de los dos bandos hostiles a las Cartas Marruecas desemboca en la emergencia de aquello que el texto reprime: el hecho de que pueda leerse como sátira dentro de un género que concierne la censura y la reforma de costumbres por medio de la risa o de lo serio. Nos percatamos entonces de que existe una preocupación por borrar cualquier identificación con la sátira, aunque ya desde el inicio del prólogo, con la referencia a Cervantes, se manifieste esta reivindicación genérica:

Desde que Miguel de Cervantes compuso la inmortal novela en que criticó con tanto acierto algunas viciosas costumbres de nuestros abuelos, que sus nietos hemos reemplazado con otras, se han multiplicado las críticas de las naciones más cultas de Europa (...) (Cadalso 1983: 77)

Esta interpretación del Quijote en términos de sátira es un rasgo de recepción que encontramos a lo largo y a lo ancho del s.XVIII español y se basa en una lectura atenta al prólogo de 1605 (Chen 1994b: 91), en donde el autor hace una declaración de intenciones en la que confiesa su objetivo de destruir las novelas de caballería. Para los ilustrados españoles, el gran valor del texto cervantino reside en que Cervantes haya podido curar, con un personaje de ficción, una afición y un vicio que causaban tantos males a la sociedad de su tiempo y, en este sentido, el Quijote se tiñe de un matiz político a los ojos de unos ilustrados que proyectaban reformas socio-políticas. Desde esta perspectiva, Francisco Aguilar Piñal apunta que "el quijotismo dieciochesco es ya una actitud beligerante que se propone abatir los re- 
siduos barrocos de la vida y de las costumbres, en nombre de la razón y del buen gusto" (1982: 210, cursiva del autor), por lo que el Quijote se lee, adquiriendo una significación política, bajo el prisma del proyecto de reformas que impulsan los ilustrados y la noción de sátira que se instituye resalta su función didactico-moral, como una manera de atacar los males de una sociedad (Ramírez-Araujo 1952: 258). Aquí, la finalidad correctiva se alía con el pacto de veracidad con el que se funda la sátira, pues el discurso satírico presupone un contrato mimético en el que el tiempo y el espacio del enunciado se homologan a la situación de su emisor (Schawartz 1985: 215) y "trata de reflejar la realidad que rodea al escritor con un criterio de autenticidad y sinceridad, aunque tal criterio venga marcado en muchas ocasiones por deformaciones ideológicas o partidistas" (Julio Rodríguez Puértolas, citado por Lasarte 1986: 79, nota 6).

La relación referencial a la que obliga la sátira entre lo que se censura y una situación histórica concreta obliga al autor satírico a buscar un compromiso, es decir, un gesto de precaución ante el mal uso de la ficción y su posible degeneración en panegírico o en crítica acerba. Y con esta finalidad, el último párrafo del prólogo lanza una precaución en términos de una captatio benevolentiae en la que el autor, amparándose todavía en esa máscara de la figura del editor, apela a la buena fe y a la sinceridad como motores de la obra que ha compuesto:

Pero mi amor propio me consolará (...) y me diré a mí mismo: yo no soy más que un hombre de bien, que he dado a luz un papel, que me ha parecido muy imparcial, sobre el asunto más delicado que hay en el mundo, cual es la crítica de una nación (Cadalso 1983: 82)

La preocupación constante del prólogo de dejar constancia de su imparcialidad política se vuelve casi una obsesión que ha obligado al autor a escamotear su responsabilidad en cuanto autor del texto (el artificio extranjerizante de un falso autor o la invención de un falso manuscrito encontrado fortuitamente) y a separarse constantemente de las dos malas interpretaciones que puede hacerse de sus cartas. Bajo tal clima de suspicacia, ¿cómo creer en su buena fe y en su sinceridad? ¿Por qué actúa así? La imparcialidad es insostenible allí donde falla la verdad y las dudas surgen. En palabras de Francesco Orlando, el gesto de precaución (oscilación en la autoría del texto, la condena de dos malas interpretaciones del texto, la insistencia en su sinceridad a la hora de tratar el tema político) tendría como finalidad escamotear la censura misma a la que puede conducir el autor del texto y, por añadidura, engañar al censor ante un libro que es por naturaleza polémico y que acarrearía problemas para quien lo firma (1980: 85) y no tanto como lo que Baquero Goyanes aduce, pues para él, los problemas los acarrearía la imparcialidad o "neutralidad crítica" que el autor arriesga (1963: 19). Esta sería entonces la tensión interna que genera la situación comunicativa de las Cartas Marruecas, como la califica Glendinning (1971) al determinar cómo el texto lo arrastra el temor a la censura en un tema que, de por sí, es candente y "una cuestión palpitante" en la España del último tercio del siglo XVIII. De ahí que, en un acto final por neutralizar cualquier reacción hostil, el autor declare su sentido patriótico y su amor imparcial que Azorín sintetizaba excelentemente, dejándose arrastrar por la programación del carácter imparcial: "ni todo lo nacional, ni todo lo extranjero" (citado por Glendinning 1962: 87). 


\section{Notas}

1. Siguiendo la terminología de Gérard Genette, un prólogo es alógrafo, toda vez que esté escrito por otra mano diferente a la del autor; sin embargo esta primera definición resulta inexacta aquí. Luego del análisis del prólogo, veremos que adquiere la categoría de prólogo alógrafo autorial auténtico, por cuanto el pretendido editor es, en realidad, el autor que se esconde bajo esta máscara. Para más detalles, $c f r$. Genette 1987: 166-9.

2. Lafarga hace un recuento exhaustivo de los viajes a tierras exóticas y desconocidas en las letras españolas e insiste en que los periódicos de la época ofrecían, para satisfacer el gusto de los lectores, noticias y comentarios sobre viajes o descripciones sobre esos países lejanos que visitaban los viajeros (1994: 177$81)$.

3. Tampoco podemos pasar por alto el gusto, en el imaginario español, por lo exótico referido a las culturas árabes del norte de Africa. Durante el siglo XVIII, abundan relatos de viajeros españoles a tierras moras; por ejemplo, Lafarga señala los siguientes: el de Jorge Juan, quien viaja como embajador real a Marruecos y su diario, entre crónica y relación diplomática, se publica hasta principios del s.XIX (Madrid 1816); también se encuentra el de Domingo Badía, quien es auspiciado por el príncipe de la Paz y viaja por el Magreb, primero por Marruecos, asumiendo la identidad de un árabe, Viajes de Alí Bey por Africa y Asia (1a. edición en francés, París 1814; en español, Madrid 1826). Llama poderosamente la atención este cambio de identidad o esta máscara que asume el viajero para acercarse al espacio ignoto. Cfr. el excelente artículo de Anny Garcia en donde analiza las máscaras y el proceso de identidad que implican,"De Domingo Badía y Leblich a Hadj-Alí-Abou-Othman: La fausse énigme des pseudonymes", Imprévue (1), 1991: 31-42.

4. Existe otro texto epistolográfico en las letras españolas del siglo XVIII que adopta también la estrategia de lo morisco referido, aquí, a lo turco, las Cartas Turcas, de Juan Meléndez Valdés; $c f r$ al respecto de Georges Demerson, "Las perdidas Cartas Turcas de Meléndez Valdés", Bulletin Hispanique 83 (3-4), 1981: 446-62.

5. Cfr. mi artículo "Un acercamiento a la deriva hermeneútica de las Cartas Marruecas de José Cadalso". Revista de Filología y Lingüistica 22 (1), 1996: 7-15.

6. Puede confrontarse en este punto los trabajos de François Lopez y de Lucienne Domergue citados en la bibliografía.

7. Un juicio del mismo tipo se suscita en el Fray Gerundio de Campazas, cuando fray Prudencio, a propósito del sermón de Santa Orosia, intenta convencer sin éxito a Gerundio de que renuncie a componer sermones como el que recién ha predicado. Para fray Prudencio la presencia excesiva del autor mina cualquier tentativa de una censura equilibrada y seria de una obra; cuestiona la amplificatio que puede haber en materia de alabanza de un autor o de un aparato crítico demasiado voluminoso: rechaza así las censuras "adornadas de todo género de erudición" (Isla 1960: 277).

8. Debo aclarar que, según mi interpretación, se trata de una constante en textos satíricos dieciochescos, por ejemplo se encuentra en Los eruditos a la violeta del propio Cadalso y en Las exequias de la lengua española de Juan Pablo Forner.

9. A esta conclusión llego al recensar lo que dice el Diccionario de Autoridades para la entrada parcial : "(...)Vale también el que sigue el partido de otro o está siempre de su parte" (1979: 125, tomo III). Lo mismo recensa Martín Alonso para parcial: "Que juzga o procede con parcialidad, o que la incluye o denota. Que sigue el partido de otro, o está siempre de su parte" (1958: 3147-8, tomo III). 


\section{Bibliografía}

Aguilar Piñal, Francisco. 1982. "Anverso y reverso del 'quijotismo' en el siglo XVIII español”. Anales de Literatura Española . 1: 207-16.

Alborg, Juan Luis. 1980. Historia de la Literatura Española. Tomo III. Madrid: Editorial Gredos.

Alonso, Martín. 1958. Enciclopedia del idioma. Madrid: Editorial Aguilar.

Baquero Goyanes, Mariano. 1963. Perspectivismo y contraste (De Cadalso a Pérez de Ayala). Madrid: Editorial Gredos.

Berrendonner, Alain. 1981. Eléments de pragmatique linguistique. París: Editions De Minuit.

Boissier, Gastón. 1900. Cicerón y sus amigos. Madrid: La España Moderna.

Cadalso, José. 1983. Cartas Marruecas - Noches lúgubres. 7a. edición (a cargo de Joaquín Arce). Madrid: Editorial Cátedra.

Camps, Victoria. 1989. "La mentira como presupuesto”. En: Carlos Castilla del Pino (comp.), 29-41.

Capmany, Antonio de. 1786. Teatro histórico-crítico de la eloquencia española. Tomo I. Madrid: Antonio de Sancha.

Castilla del Pino, Carlos (comp.). 1989. El discurso de la mentira. Madrid: Alianza Editorial.

Chen Sham, Jorge. 1991. "La teoría del paratexto y el Fray Gerundio de Campazas: la puesta en escena de una retórica de lo liminar". Revista de Filología y Lingüística. 17 (12): $7-19$.

1994a. "El criticismo de los novatores: motor de la primera biografía cervantina, escrita por Gregorio de Mayáns”. Revista de Filología y Lingüística. 20 (2): 7-17.

1994b. "El intertexto cervantino en un texto dieciochesco: el Fray Gerundio de Campazas". Káñina, Revista de Artes y Letras. 18 (2): 85-94.

1995. "Perfecit y denegación final del contrato historiográfico en el Fray Gerundio de Campazas”. Revista de Filología y Lingüística. 21 (2): 83-90.

1996. "Un acercamiento a la deriva hermenéutica de las Cartas Marruecas de José Cadalso". Revista de Filología y Lingüística 22 (1):d 7-15. 
Demerson, Georges. 1981. "Las perdidas Cartas Turcas de Meléndez Valdés". Bulletin Hispanique. 83 (3-4): 446-62.

Diccionario de Autoridades (edición facsímil). 1979. Madrid: Editorial Gredos.

Didier, Béatrice. 1987. Le siècle des Lumières. París: MA Editions.

Domergue, Lucienne. 1982. Censure et lumières dans l'Espagne de Charles III. París: Editions du CNRS.

García, Anny. 1991. "De Domingo Badía y Lebrich a Hadj-Alí-Abou-Othman: La fausse énigme des pseudonymes". Imprévue. (1): 31-42.

Genette, Gérard. 1987. Seuils. París: Editions du Seuil.

Glendinning, Nigel. 1962. Vida y obra de Cadalso. Madrid: Editorial Gredos.

1971. "Structure in the Cartas marruecas of Cadalso". En Peter Hughes y David Williams (eds.), 51-76.

Hughes, Peter y David Williams (eds). 1971. The Varied Pattern: Studies in the Eighteenth Century. Toronto: A.M. Hakkert.

Isla, José Francisco de. 1960. Fray Gerundio de Campazas. Tomo I. Madrid: Editorial Espasa-Calpe (edición de Russel Sebold).

Lafarga, Francisco. 1994. "Territorios de lo exótico en las letras españolas del s.XVIII". Anales de Literatura Española. 10: 173-92.

Lasarte, Pedro. 1986. "El retrato y la alegoría satírico-burlesca en Rosas de Oquendo". Lexis. $10(1)$ :

Lopez, François. 1976. Juan Pablo Forner et la crise de la conscience espagnole au XVIIIè siècle. Burdeos: Institut d'Etudes Ibériques et Ibéroaméricaines.

Maravall, José Antonio. 1966. "De la Ilustración al Romanticismo: El pensamiento político de Cadalso". Mélanges à la mémoire de Jean Sarrailh, 81-96. Tomo I. París: Centre de Recherches de l'Institut d'Etudes Hispaniques.

Mestre, Antonio. 1986. "Historia crítica y reformismo en la Ilustración Española". En La Ilustración Española. Alicante: Instituto Juan Gil-Albert, 125-139.

Orlando, Francesco. 1981. "Rhétorique des Lumières et dénégation freudienne". Poétique. (41): 78-89. 
Pérus, Françoise. 1981. "La formación ideológica estético-literaria (Acerca de la reproducción y transformación del "efecto estético")". Revista Iberoamericana .(114-115): 255-75.

Ramírez-Araujo, Alejandro. 1952. "El cervatismo de Cadalso". The Romanic Review. 43: 256265.

Schartz Lerner, Lía. 1985. "En torno a la enunciación en la sátira: los casos de El Crotalón y los Sueños de Quevedo". Lexis . 9 (2): 209-27.

Sebold, Russell P. 1974. Cadalso: el primer romántico "europeo" de España. Madrid: Editorial Gredos.

Zavala, Iris M. 1983. "Inquisición, erotismo, pornografía y normas literarias en el siglo XVIII". Anales de Literatura Española . 2: 509-529.

1984. "Viaje a la cara oculta del setecientos". Nueva Revista de Filología Hispánica. 33 (1): 4-33. 